\title{
CONSERVAÇÃO DE SEMENTES DE AMENDOIM EM CÂMARA FRIA E SECA ( $\left.{ }^{1}\right)$
}

\author{
ANGELO SAVY FILHO $(2,5)$, ANTONIO AUGUSTO DO LAGO $(3,5)$, \\ EDUARDO ZINK $\left({ }^{4}\right)$, MARCELO APARECIDO NUNES GERIN $\left({ }^{2}, 5\right)$, \\ JOCELY ANDREUCCETTI MAEDA $\left({ }^{3}\right)$ e LUIZ FERNANDES RAZERA $\left({ }^{3}, 5\right)$
}

\begin{abstract}
RESUMO
Sementes de amendoim (Arachis hypogaea L.) do cultivar Tatu, produzidas no Centro Experimental de Campinas, no perfodo "das águas" do ano agrícola 1970/1971, foram descascadas manual e mecanicamente, tratadas com fungicida e mantidas em câmara de armazenamento regulada a $15^{\circ} \mathrm{C}$ e $35 \%$ de umidade relativa por 36 meses. Sementes descascadas manualmente apresentaram, ao final desse período, germinação de $87 \%$, e as descascadas mecanicamente, de $62 \%$. Os resultados mostraram ser possível conservar sementes tratadas de amendoim, nas condiçöes mencionadas, por ate 36 meses para as descascadas manualmente, e por ate 24-30 meses, para as descascadas mecanicamente.
\end{abstract}

Termos de indexação: amendoim, Arachis hypogaea L., sementes, armazenamento; armazenamento, frio e seco.

(1) Recebido para publicação em 31 de dezembro de 1985.

(2) Seçäo de Oleaginosas, Instituto Agronômico de Campinas (IAC), Caixa Postal 28, 13001 Campinas (SP).

(3) Seção de Sementes, IAC.

(4) Divisāo de Biologia Fitotécnica, IAC.

(5) Com bolsa de suplementação do $\mathrm{CNPq}$. 


\section{INTRODUÇÃO}

A preservação de germoplasma, nos últimos anos, vem recebendo relativa atenção no Brasil, em vista não só da maior conscientização da necessidade de preservação dos recursos genéticos nacionais, como também da maior disseminação pelo país de trabalhos de melhoramento de plantas. $\dot{E}$ grande, portanto, a necessidade do estudo de formas eficientes, práticas e econômicas de manutenção de germoplasma, a fim de torná-lo disponivel para uso presente e futuro dos que trabalham com desenvolvimento de cultivares (ITO, 1972; JAMES, 1972; CAMARGO et alii, 1974; FAGUNDES, 1982).

No caso do amendoim, ainda são poucos os dados sobre a conservação das sementes, notadamente por periodos relativamente longos, necessários ao bom funcionamento de um banco de germoplasma.

ZINK et alii (1962) verificaram a possibilidade da conservação de sementes de amendoim, beneficiadas manual e mecanicamente, tratadas e não tratadas com fungicida e mantidas em condiçōes comuns de armazém por doze meses. Concluíram os AA. que as sementes que mantiveram o poder germinativo mais alto durante o período foram aquelas beneficiadas manualmente e tratadas com fungicida; resultados não tão positivos, porém razoáveis, foram conseguidos com as sementes beneficiadas mecanicamente, desde que também tratadas com fungicida.

TELLA et alii (1976) observaram que sementes de amendoim descascadas mecanicamente, tratadas com fungicidas, mantidas a temperatura ambiente e com umidades de 4,5 e 6,0\%, apresentaram porcentagens médias de germinação de 63 e 80 respectivamente, após 22 meses de armazenamento.

O presente trabalho teve por objetivo verificar a possibilidade de conservar sementes de amendoim com alto poder germinativo, quando mantidas em câmara fria e seca, por 36 meses.

\section{MATERIAL E MÉTODOS}

Foram utilizadas sementes de amendoim do cultivar Tatu, produzidas no Centro Experimental de Campinas no periodo "das águas" do ano agrícola 1970/71. A porção inicial de sementes, ainda nas vagens, foi homogeneizada e dividida em duas subporções: uma foi descascada manualmente e outra, submetida a descasque mecânico. As sementes das duas subporções, com aproximadamente $5 \mathrm{~kg}$ cada uma, foram, depois de limpas e peneiradas da mesma forma, tratadas com o fungicida Neantina Seco $(1,5 \% \mathrm{em} \mathrm{Hg}$ na forma de acetato mercurifenílico) na dosagem de $0,2 \%$ em peso de semente. Após o tratamento, as sementes foram embaladas em sacos de pano e mantidas em câmara regulada a temperatura e umidade relativa constantes de $15^{\circ} \mathrm{C}$ e $35 \%$ respectivamente. 
As determinações do poder germinativo foram realizadas aos $0,12,15$, $18,21,24,30$ e 36 meses, utilizando-se quatro repetiçőes de 50 sementes cada uma, em substrato rolo de papel especial para germinação, a temperaturas alternadas de $20-30^{\circ} \mathrm{C}$, com a primeira contagem aos cinco dias e a última aos dez dias, de acordo com as Regras para Análises de Sementes (BRASIL, 1980).

\section{RESULTADOS E DISCUSSÃO}

No quadro 1, verifica-se que o descasque mecânico foi prejudicial à conservação das sementes, pois, com exceção do teste inicial, a germinação daquelas descascadas mecanicamente foi, em períodos correspondentes, sempre inferior à das descascadas manualmente. $O$ tegumento frágil e a natureza pouco resistente dos cotilédones tornam a semente de amendoim muito vulnerável a danos mecânicos, facilitando a invasão de microorganismos e conseqüente deterioração rápida, como já relatado por HIGGINS \& BAYLEY (1959), ZINK et alii (1962), BASKIN \& DELOUCHE (1971) e TELLA et alii (1976). Por essa razão, o tratamento fungicida de sementes de amendoim é praticamente obrigatório, pelo menos imediatamente antes do plantio (BACCHI \& CANECCHIO FILHO, 1954; ZINK et alii, 1962; LAGO et alii, 1976; TELLA et alii, 1976).

Deve-se ressaltar que, atualmente, está proibido o uso do fungicida Neantina Seco. Sua aplicação seguiu as recomendações da época, baseadas em trabalho realizado por ZINK et alii (1962).

QUADRO 1. Porcentagens de germinação de sementes de amendoim, descascadas manual e mecanicamente, tratadas com fungicida e armazenadas por 36 meses em câmara a $15^{\circ} \mathrm{C}$ e $35 \%$ de umidade relativa

Meses de

Forma de descasque

armazenamento

Manual Mecânica

\begin{tabular}{|c|c|c|}
\hline $0 \ldots \ldots \ldots \ldots \ldots \ldots \ldots \ldots$ & 95 & 95 \\
\hline 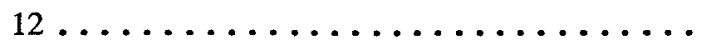 & 96 & 91 \\
\hline $15 \ldots \ldots \ldots \ldots \ldots \ldots \ldots \ldots$ & 96 & 86 \\
\hline $18 \ldots \ldots \ldots \ldots \ldots \ldots \ldots \ldots \ldots$ & 95 & 90 \\
\hline $21 \ldots \ldots \ldots \ldots \ldots \ldots \ldots \ldots \ldots \ldots$ & 94 & 91 \\
\hline $24 \ldots \ldots \ldots \ldots \ldots \ldots \ldots \ldots$ & 93 & 84 \\
\hline $30 \ldots \ldots \ldots \ldots \ldots \ldots \ldots \ldots$ & 86 & 83 \\
\hline $36 \ldots \ldots \ldots \ldots \ldots \ldots \ldots \ldots \ldots \ldots \ldots \ldots \ldots \ldots$ & 87 & 62 \\
\hline
\end{tabular}


As sementes descascadas manualmente mantiveram o poder germinativo praticamente inalterado até os 24 meses, tendo havido apenas um pequeno decréscimo nos dois últimos periodos, porém apresentando a germinação de $87 \%$ ao final dos 36 meses de armazenamento.

As sementes submetidas ao descasque mecânico sofreram um decréscimo sensivel na germinação a partir dos 21 meses, apresentando $83 \%$ aos 30 meses; nos últimos seis meses, o decréscimo em germinação dessas sementes foi acentuado: $62 \%$ aos 36 meses.

É possivel concluir-se, portanto, que é perfeitamente viável conservar sementes tratadas de amendoim a $15^{\circ} \mathrm{C}$ e $35 \%$ de umidade relativa, até por 36 meses para as descascadas manualmente, ou por até 24-30 meses para as que passam por descasque mecânico. Dessa forma, verifica-se que não é necessário proceder-se ao plantio anual das sementes para sua manutenção.

\title{
SUMMARY
}

\section{PEANUT SEED PRESER VATION IN COLD AND DRY CHAMBER}

\begin{abstract}
Peanut (Arachis hypogaea L.) seeds of the cultivar Tatu, produced at the Centro Experimental de Campinas, in the 1970/1971 crop year, were manually and mechanically shelled, treated with fungicide, and kept in a store-room maintained at $15^{\circ} \mathrm{C}$ and $35 \%$ relative humidity for a period of 36 months. Manually shelled seeds presented, after 36 months of storage, the germination of $87 \%$, while those mechanically shelled exhibited in the same period, the germination of $62 \%$. Results showed that it is possible to preserve treated peanut seeds in the above mentioned conditions for at least 36 months when manually shelled, and for at least, 24-30 months when mechanically shelled.
\end{abstract}

Index terms: storage, cold and dry, seeds, peanut, Arachis hypogaea L.

\section{REFERÊNCIAS BIBLIOGRÁFICAS}

BACCHI, O. \& CANECCHIO FILHO, V. A desinfecção de sementes de amendoim. Bragantia, Campinas, 14:I-II, 1954. (Nota, 1)

BASKIN, C.C. \& DELOUCHE, J.C. Effects of mechanical shelling on storability of peanut (Arachis hypogaea L.) seed. Proceedings of the Association of Official Seed Analysis, 61:78-84, 1971.

BRASIL. Ministério da Agricultura. Escritório de Produção Vegetal. Equipe Técnica de Sementes e Mudas. Regras para análise de sementes. Brasilia, 1980. 188p.

CAMARGO, C.P.; GREGG, B.R. \& LINGERFELT, C.W. Banco Nacional de Germoplasma. Brasília, Ministério da Agricultura, AGIPLAN, 1974. 40p. 
FAGUNDES, S.R.F. Conservação de germoplasma-semente. Brasília, CENARGEN/ EMBRAPA, 1982. 9p.

HIGGINS, B.B. \& BAYLEY, W.K. Peanut seed and seed treatments. Athens, University of Georgia College of Agriculture, 1959. 93p. (Mimeograph Series N.S., 70)

ITO, H. Organization of the National Seed Storage Laboratory for Genetic Resources in Japan. In: ROBERTS, E.H., ed. Viability of seeds. Syracuse, Syracuse University Press, 1972. p.405-416.

JAMES, E. Organization of the United States Seed Storage Laboratory. In: ROBERTS, E.H., ed. Viability of seeds. Syracuse, Syracuse University Press, 1972. p.397-404.

LAGO, A.A.; ORTOLANI, D.B.; ZINK, E. \& FERNANDES, C.O. Efeito de diversos tratamentos fungicidas na longevidade de sementes de amendoim. Semente, Brasilia, 2(2):26-31, 1976.

TELLA, R.; LAGO, A.A. \& ZINK, E. Efeito de diversos níveis de umidade e tratamento fungicida na longevidade de sementes de amendoim. Bragantia, Campinas, 35:335-342, 1976.

ZINK, E; CORAL, F.J. \& TELLA, R. Estudos sobre a conservação de sementes. X. Amendoim. Bragantia, Campinas, 21:CLIX-CLXV, 1962. (Nota, 27) 